\title{
Study on Option Price Model of the Transaction of Information Commodities
}

\author{
Changping HU, Xianjun QI \\ Center for Studies of Information Resources, Wuhan University, Wuhan, China. \\ Email: xianjun.qi@gmail.com
}

Received August 25, 2009; revised September 29, 2009; accepted November 1, 2009.

\begin{abstract}
The option is viewed as an important tool of setting price in accordance with objective benefits and actual effectiveness of information commodities, as ensures that the holder of the option right acquires more benefits in the favorable market and reduces losses in the adverse market. And the information market, as a kind of typical monopolistic and competitive market, is especially adequate for introducing the option theory to set more reasonable price and further to improve the operational efficiency of information market. Hence, it is quite necessary to apply the option theory to the transaction of information commodities. In this paper, after analyzing the applicability of the option theory to the information market and studying the option price of information commodities, the authors put forward the option price model of the transaction, followed by a case study to demonstrate the validity of the model.
\end{abstract}

Keywords: Information Commodities, Market Mechanism, Option Pricing, Transaction Model

\section{Introduction}

With the development of commodity economy, incomplete market information, which creates difference value between the cost and the profit of information searching, and which has its special value, gradually evolves into a form of independent commodity [1]. And information commodities inevitably promote the emergence and the development of information market [2]. As the product of information commercialization, information market is not only an independent and physical commodity market, but also an invisible factor market included in other markets [3]. Therefore, in the narrow sense, information market refers to as some places, where people trade information commodities at a certain period of time; while in the broad sense, it refers to all the relationships between the supply and the demand of information commodities, involving the whole course and the all fields of the circulation of information commodities, from the production to the consumption.

Information market, like the material market, could only operate formally with the complete market systems and flexible market mechanisms, namely, the supply and demand mechanism, the price mechanism, the competitive mechanism, risk mechanism, management mechanism and other mechanisms [4]. And it is the price mechanism that serves as the most effective way of resources allocation in the market economy. The main reason is that the price, as the most sensitive signal in the market, could accurately and timely reflect the imbalance between the supply and the demand of information commodities distributed to many different directions of utilization to maximize the effectiveness. Therefore, pricing is the primary task in the transaction of information commodities.

Regarding the price of information commodities, there have been several pricing methods such as multiple pricing [5], bundle pricing, discriminatory pricing, Ramsey pricing and integrated pricing strategies etc. [6]. All of them are classified as Net Present Value (NPV) methods, based on the traditional pricing theories, neglecting the impact of market uncertainty on the transaction of information commodities. Since information commodities have the characteristics of monopoly, externalities, public product properties and a shorter life cycle, information asymmetry are more common and information market are more uncertain. Thus the above pricing methods do not always make right prices identical with the real value of information commodities [7].

In the middle of the last century, many researchers and managers found that discounted cash flow methods, represented by NPV, led to ineffective resources allocation [8]. Shortly afterwards many scholars, like Louis Bachelier, Paul Samuelson, Fischer Black, Myron Scholes, Robert Merton and so on, began to seek other solutions and put forward several transaction models under the 
uncertainty conditions, which made a significant contribution to option research. After analyzing those models, it is easy to draw the conclusion that the option theory had two obvious advantages in resolving the transaction of information commodities: the one is that the option theory dealt with the uncertainty under the condition of observing the principles of the classic economics and mathematics; the another is that the option method, replacing the inaccuracy with the complexity, is almost applicable to every market.

Moreover, in the information market, the option of information commodities can objectively reflect the impact of the uncertainty of information market and the flexibility of decision-making on the price and the value of information commodities, by assessing the value of options, by analyzing the costs and profits of the both parties and by setting a reasonable price, so as to achieve the optimal allocation of information resources.

\section{The Applicability of the Option Theory to Information Market}

\subsection{The Option Theory}

The option theory had been gradually developed in the long-term practice of solving the uncertainty of the price in the future market. Essentially, an option is also called a option contract, which stipulates the right of the seller or the buyer to choose to sell or buy a certain number of underlying assets such as portfolio, financial assets and physical assets at a fixed price within a prescribed time. Thus, the option is no mere a financial derivatives, but rather an objective right to choose. Obviously, the option is a tool of transaction and pricing in the future market [9].

Previous studies suggested that the real option is derived from the financial option. Its core idea is that investors should maximize the value of the project by means of some market-based methods instead of subjective probability methods and utility functions when they determine the value of investment opportunities and choose the optimal investment strategy. Simply, the real option is a kind of realistic option defined by the option concept. According to different holders of the right, options are divided into a call option and a put option: the former is the right that the option buyer purchases underlying assets in terms of stated price and quantity within validity of the option contract, and the latter refers to the right to sell the underlying assets under the same conditions; While according to the difference of exercise time, options are divided into American option and European option: the former specifies buyers can exercise options on or prior to any given trading day, and the latter is just the opposite. Actually, the buyers of American call option can flexibly choose the best time that is most advantageous to them, to exercise options according to the market shift and the actual demand.
The most distinctive feature of the option is that an option grants the exercise right, rather than the obligation, to the option buyer in the form of the contract. That is, option buyers may make profits from the transaction when the price of the underlying asset is higher than the exercise price, on the contrary, they just avoid more losses (aside from the value of the option) by giving up their option rights. That is why the method of the option is specifically suitable for the high-risk and strong flexible market. Especially, in the market with asymmetric information, the option can help to reduce the risk caused by the uncertainties of the supply and the demand, to add the effectiveness of information commodities, and further to reduce transaction costs by improving the market transaction.

\subsection{The Option Features of Information Commodities}

Some experts on the theory of the real option, like Dixit, maintained that the irreversibility, the uncertainty and the selectivity of the investment were just theoretic premise of the research on real options [10]. In addition, as the main form of information resources in the market economy, information commodities also fulfill the given precondition: firstly, most information commodities are technology-based or experience-based commodities, requiring consume a majority of intangible capital that is a part of submersion capital, difficult to recover invested costs; secondly, as invisible values of information commodities, which often attach to material commodities, do not directly create values, and useful values usually depend on their own values and on the specific use conditions, information market fill with many uncertainties that are associated with the price, the quantity of supply and demand, the quality as well as effectiveness and that reduce the accuracy of assessing the real value of information commodities; thirdly, the production and the transaction of information commodities at different times may result in quite different profits and risks due to the long production time, the short life cycle, and the unpredictable factors in information market. In a word, the option of information commodities in the information market, an invisible market, where both of the time and the form of the transaction are extremely flexible, could be regarded as the American option. The option holders of information commodities maybe obtain more market opportunities or reduce less losses by changing the operating scale, investing periodically, delaying, giving up the option, and so on.

\subsection{The Function of the Option in Information Commodities Transaction}

In the information market, various market mechanisms are regulating the whole transaction course and the all economical relationships to realize market equilibrium. 
According to western economics, market equilibrium refers to that interrelated economic subjects, who start from their maximal welfare, interact on each other continuously to adjust market parameters until the whole economic system come up to a stable state. In theory, the above market equilibrium is a sort of "point equalization" that could realize Pareto Optimality. However, in the real information market, the price of information commodities cannot automatically regulate to a balance between supply and demand, but to a certain range deviating from each other. Therefore, information market equilibrium is a kind of "domain equalization", which is not able to fully realize ideal Pareto Optimality. The main reason is that information commodities have the following three characteristics of indivisibility, externalities and uncertainty [11], and the first two issues could be solved by pricing with marginal cost and by separating the social costs (profits) from individual costs (profits), requiring use options to solve the third one to achieve the transaction in the uncertain information market.

It is well known that the option promotes the transaction mainly by diverting, avoiding risks and regulating price. Researches indicated that the option model could simulate optimal information system [12], and that the option method could help to solve the problem of venture capital investment of information technologies [13]. Yet, in the uncertain information market, the price cannot objectively reflect the real value of information commodities. Furthermore, it is difficult for two parties to reach an agreement owing to the higher risk and the wider fluctuation margin, which leads low market efficiency. However, with an option granting exercise right stead of the obligation, option holders could transfer risks to their counterparts. And this way of transaction provides a special insurance, namely, reducing losses under the adverse condition and obtaining more profits under the favorable condition in virtue of the option of information commodities, and is bound to ease the worries of traders, reduce transaction costs, simplify the transaction process and further to promote the circulation of information commodities.

\section{The Option Price of Information Commodities}

The theory of option price is one most important achievements of modern finance theory. In 1997, having put forward the theory of option price, Myron Scholes, a Professor of Stanford university and Robert C. Merton received Nobel Prize for Economics of the year. And then the formula of option price-Black-Scholes, which is view as one of successful models of applied mathematics in social science domain, has been used widely for its simple operation and relatively accurate results [14]. Although it was proposed aiming at the European option at first, it could be quickly extended into American option that is able to pay the dividend in the option period [15], and then:

The call option price is:

$$
V_{\mathrm{t}}=S N\left(d_{1}\right)-K e^{-f t} N\left(d_{2}\right)
$$

The put option price is:

$$
P_{t}=K e^{-f t} N\left(-d_{2}\right)-S N\left(-d_{1}\right)
$$

Where, $d_{1}=\frac{\ln (S / K)+\left(f+\delta^{2} / 2\right) t}{\delta \sqrt{t}}$,

$d_{2}=d_{1}-\delta \sqrt{t}, \quad N(d)=\frac{1}{\sqrt{2 \pi}} \int_{-\infty}^{d} e^{-\frac{t^{2}}{2}} d_{t}, \quad N\left(d_{1}\right)$ and $N\left(d_{2}\right)$ respectively stands for the cumulative distribution function of standard normal distribution of $d_{1}$ and $d_{2}$, whose value may be acquired by inquiring the normal distribution table; $S$ is the current price of underlying assets; $K$ is the exercise price of underlying assets; $f$ is the risk-free profit margin, $\delta$ is the profitability of underlying assets.

In the information market, however, information commodities are mainly divided into two categories: the first one, independent of physical products, could be exchanged in a transaction without transferring the original physical carriers, such as knowledge and decision; the second one, integrated with physical carriers, carries out a transaction which often accompanies by the exchange of physical commodities, for example, a book or a CD-ROM. Clearly, for the latter, the real value of information commodities is difficult to separate from in the whole value. Then this paper is aimed at the first information commodity, which is independent of physical carriers. Moreover, the meaning of each variable of information market is quite different from those of general physical market. For example, the effective period of call options of physical commodities does not ran over the time of market transaction, meanwhile, information commodities are on the other hand. Although these produced information commodities would be marketed immediately, their effectiveness cannot accomplish right now. As thus people do not regard variable prices within a short time as the foundation for the decision whether to purchase information commodities. Instead, they mainly consider the following two issues in the long run: how much effectiveness and risks would information commodities bring about? Could they achieve expected profits? Now, if the full time from purchasing to using is assumed to be an effective option period, represented by $t$, accordingly, $\delta$ represents the value fluctuation ratio of information commodities (expressed by standard deviation of expected rate of return ), $S$ represents the expected cash value of information commodities, $K$ represents the cash value of information commodities, 
$V_{\mathrm{t}}$ represents the expected benefits of information commodities. Evidently, if $V_{\mathrm{t}}$ was less than zero or was lower than the expected, buyers would not purchase the commodities.

\section{The Transaction Model of Option Price}

Absolutely, the price is the most sensitive signal of market change and correspondingly, the price mechanism is the most effective transaction mechanism in the market economy. Under the function of the option, the price could objectively reflect the supply and the demand of information commodities, the competitive situation, the management performance, as well as the risk index of development and utilization. And it helps to improve the operational efficiency of information market and further to promote the optimal allocation of information resources. In other words, the option devotes to achieve the rational allocation of information commodities by pricing.

However, most information markets serve as seller's market, in which information asymmetry is very common, just for buyers' lack of important information including commodities, markets and seller's credibility. Hence, sellers often have a comparative advantage during the transaction, which is carried out mostly based on the price set by them. In this paper, taking a seller's market as an example, the authors constructed the option price model of the transaction of information commodities and then analyzed how the option optimized the model in order to improve the transaction in the information market.

\subsection{The Seller Price}

In the information market, $P_{S}$ is used to stand for the price set by the seller (a reasonable price, instead of exorbitant price). And the seller consider the two main determinants of production costs $\left(C_{P}\right)$ and the dividend of expected additional profits $\left(C_{H}\right)$, where $C_{P}$ includes three parts: the cost of material carriers $\left(C_{1}\right)$, the consumption of active labors $\left(C_{2}\right)$ and the opportunity cost

$\left(C_{3}\right.$ ), namely, $C_{P}=a_{1} C_{1}+a_{2} C_{2}+a_{3} C_{3}$, where, $a_{1}$, $a_{2}$ and $a_{3}$, whose value is between 0 and 1 , respectively stand for the corresponding weight of the cost. They are affected by some factors like the way of specific transaction, negotiation skills, the effectiveness of commodities and the expected values of both parties.
In addition, $C_{H}$ is determined by the two parts: the expected additional benefits $(\mathrm{R})$ and the proportional coefficient of the dividend (L). Thus, $\mathrm{R}$ is equal to the sum of additional economic profits caught by information commodities of each year. However, information commodities usually represent themselves in the form of techniques, knowledge, recipes and other intangible assets, which cannot create economic values directly, but enhance productivity and benefits by improving production processes. As a result, it is very hard to assess how much economic values and effectiveness on earth the information commodities brought about in the short time. Therefore, $\mathrm{R}$ is just estimated value or reference value of the industry during transaction. Besides, the inflation is not neglected, and it is indispensable that cash flows should be discounted to the present by a given discount rate r. Thus, additional profits received by using the method of net present value (NPV), are as follow:

$$
R=\sum_{t=1}^{N} \frac{b_{1} \cdot b_{2} \cdot b_{3}\left(G_{t}-G_{0}\right)}{(1+r)^{t}} \times W T
$$

Where, $b_{1}$ is cost factor, $b_{2}$ is the factor of quality $\&$ performance, $b_{3}$ is the sales factor, $G_{t}$ is the production capacity of the buyer after $\mathrm{t}$ years, $G_{0}$ is the production capacity of the buyer before purchasing the information commodity, $r$ is the discount factor of the currency, $\mathrm{W}$ is the profit of per unit of production after purchasing and $\mathrm{T}$ is the monopoly coefficient of the information commodity. And the proportional coefficient of the dividend (L) have to balance the profits of both sides and depend on the funding of the corresponding supporting facilities, noted as $C_{M}$, namely, the proportional coefficient of the dividend $(\mathrm{L})$ is equal to the ratio of $C_{P}$ :

$$
L=\frac{C_{P}}{C_{M}} \times 100 \%=\frac{C_{P}}{Q^{\prime} \cdot C} \times 100 \%
$$

In the above formula, $C_{M}$ is the application cost of the buyer, assessed by experts, namely, $C_{M}=Q^{\prime} \cdot c, Q^{\prime}$ is the production of the buyer after using the information commodities, $C$ is the application cost of the buyer after using the information commodities. And the formula of the proportional coefficient of the dividend (L) and the seller price $P_{S}$ are as follows:

$$
\begin{gathered}
C_{H}=L \cdot R=\frac{C_{P}}{Q^{\prime} \cdot c} \cdot \sum_{t=1}^{N} \frac{b_{1} \cdot b_{2} \cdot b_{3}\left(G_{t}-G_{0}\right)}{(1+r)^{t}} \times W T \times 100 \% \\
P_{S}=C_{P}+C_{H}=\left(a_{1} C_{1}+a_{2} C_{2}+a_{3} C_{3}\right)+\frac{C_{P}}{Q^{\prime} \cdot c} \cdot \sum_{t=1}^{N} \frac{b_{1} \cdot b_{2} \cdot b_{3}\left(G_{t}-G_{0}\right)}{(1+r)^{t}} \times W T \times 100 \%
\end{gathered}
$$

Obviously, the upper limit of the seller price: 


$$
P_{S \max }=\left(a_{1} C_{1}+a_{2} C_{2}+a_{3} C_{3}\right)+\sum_{t=1}^{N} \frac{b_{1} \cdot b_{2} \cdot b_{3}\left(G_{t}-G_{0}\right)}{(1+r)^{t}} \times W T
$$

The bottom limit of $P_{S}$ is: $P_{S \min }=a_{1} C_{1}+a_{2} C_{2}+a_{3} C_{3}$, where $P_{S}$ ought to meet the equation: $P_{S \min } \leq P_{S} \leq P_{S \max }$.

\subsection{The Transaction Price}

For buyers, the lower the transaction price is, the more profits they obtain. However, their expected price can not be lower than the lowest expected price of the seller, or it cannot reach a deal. Meanwhile, buyers set a fuzzy value of expected price which is generally higher than the bottom limit of the seller price provided that the transaction is concluded, that is, the two parties would soon reach a deal at a transaction price $\mathrm{P}$ when the seller price was absolutely propitious to achieve the expected return of the buyer or much lower than the expected price. Nevertheless, it is rare. Instead, there is a more general situation that the seller price is so high that the consumer surplus of the buyer is less than the expected return. In this case, whether to reach a deal or not depends on whether the consumer surplus of the buyer come up to the expectation at the lowest price set by the seller. Then represented by letters, it is showed as follows. Substitute the lowest price of the seller $\left(P_{S \min }\right)$ into the formula of the option price to compute the value of $V_{\mathrm{t}}$, which is not less than the expected return to reach a deal after the bargain, otherwise, the deal is failed.

$$
\varphi=\frac{V}{S}=N\left[\frac{\left(f+\delta^{2} / 2\right) \sqrt{t}}{\delta}\right]-e^{-f t} N\left[\frac{\left(f-\delta^{2} / 2\right) \sqrt{t}}{\delta}\right]
$$

In fact, it is very complicated to introduce the model of Black-Scholes to compute comprehensive evaluation of the option, an absolute value of quantities. To simplify the calculation, it is advisable to transform the above formula into the expression of relative options. Furthermore, the difference between the present value of future profits (S) and further out-of-pocket (K) determines whether the buyer purchases the certain information commodities or not. And then we can compute the option price $(\mathrm{V})$ of the critical point (i.e. $\mathrm{S}=\mathrm{K}$ ), then the ratio of the price $(\mathrm{V})$ and the value of profits (S) is just the impact factor of the option price, noted as $\varphi$. Now, substituting the equation of $\mathrm{S}=\mathrm{K}$ to formula 1 , we can see:

The traditional methods of evaluation regarded costincome ratio as the relative value without regard to the option. When options that exist objectively are considered, the impact of the option price on the value of information commodities is expressed as $\frac{S}{K} \cdot \varphi$, and then the relative evaluation value of the real options $(g)$ similarly is estimated as follows:

$$
g=\frac{S}{K}\left(1+\frac{S}{K} \varphi\right)
$$

It's crucial, therefore, to compare the value of $g$ with 1 , that is, if $g>1$, the buyer would purchase the commodity; otherwise, the buyer would give up the transaction when $g<1$.

\section{Case Study}

Here, we assume that some company (A) has developed the new generation of ERP, whose costs of material carrier are $\$ 50$ million, the costs of active labor are $\$ 250$ million, the opportunity costs are $\$ 300$ million, and which could add a profit of $\$ 100$ million per year within the service life of 10 years, when the monopoly coefficient equal to 0.2 . In the meantime, another company (B) that would purchase the ERP of A, needs to cost $\$ 500$ million to allocate the corresponding equipments and staff. At this time, the fluctuation ratio of the value of the ERP system $\delta$ is $30 \%$ ( $\delta=30 \%)$, and risk free rate $(f)$ is $8 \%(f=8 \%)$.

For company A: the cost of production $C_{P}=50+250+$ $300=600$ (million dollars); the rate of profit commission $=600 /(600+500)=0.545$; the expected profit is 1000 million dollars; the expected profit commission $C_{H}=$ $(1000+600) \times 0.545 \times 0.2=174.4$ (million dollars); Then reasonable price of $\mathrm{A}$ is $P_{S}=600+174.4=774.4$ (million dollars), and the floor price accepted by $\mathrm{A}$ is $\$ 600$ million while its highest price should be $1000+600=1600$ million dollars, i.e., the range of transaction price $\mathrm{P}$ meeting the requirements of $600<\mathrm{P} \leq 1600$ (million dollars).

What if we use the method of DCF (Discounted Cash Flow) to compute these parameters?

Well, the minimum amount company B need to pay is $600+500=1100$ million dollars, and correspondingly, its profit is $100 \times 10=1000$ million dollars. Clearly, in that case, B would not purchase the ERP system since income is less than the expense.

\section{Conclusions}

The real option is not so much a tool as a way of thinking, which is greatly able to provide people with a scientific, dynamic and strategic analysis framework, and which is appropriate not only for evaluating the value and the price but for arranging optimal actions to avoid risks. Absolutely, it is the option with above excellent features that has outstanding advantages in the information mar- 
ket, where the option can effectively promote reasonable distribution of information commodities in the aspects of the time, the space and the type in order to maximize their effectiveness. Therefore, from the standpoint of economic profits, the option mainly regulates the benefits of market players to optimize the price model in the virtue of the price mechanism.

In a word, this paper proposed that information commodities had the characteristics of the option, that options played an important role in commodities transaction, and that the classic model of the option price was applied to set the option price of information commodities. Additionally, taking for an example of information commodities, we analyzed how the call option exerted its influence to buyers' decision-making, as is of importance in guiding the activities of information economy. However, there are several problems to be further elaborated in the future, for instance, combining the option theory with the game theory to investigate some new laws and features of information commodities in the information market and further to improve the operational efficiency.

\section{Acknowledgments}

This paper is supported by the major project of National Social Science Foundation of China under Grants 06J2D0032.

\section{REFERENCES}

[1] H. Q. Ma and C. Zong, "Analysis on the implementation efficiency problems and countermeasures about the policy and regulations for the network information resources construction and location," Library and Information, Vol. 10, pp. 31-35, 2006.

[2] X. J. Zha, "The allocation of resources and sharing of information," Wuhan University Press, Wuhan, 2008.

[3] F. C. Ma, G. Li, and X. J. Zha, "Information resources management," Wuhan University Press, Wuhan, 2001.

[4] W. Y. Xu and L. N. Li, "Study on information resources effective allocation under the conditions of market economy," Journal of Information, Vol. 11, pp. 128-131, 2005.

[5] L. Huan and Y. Jiang, "Research on the Multi-prices Pricing Model of Information Product," Finance and Economics, Vol. 4, pp. 63-66, 2002.

[6] F. C. Ma and X. G. Wang, "Pricing strategies and methods of information commodities," Information Studies: Theory \& Application, Vol. 3, pp. 285-287, 2003.

[7] F. Ancarani and V. Shankar, "Price levels and price dispersion on the internet: A comparison of pure play internet, bricks-and-mortar, and bricks-and-clicks retailers," Business Research Center Working Paper, 2002.

[8] L. Trigeorgis, "Real options: Managerial flexibility and strategy in resource allocation," MIT Press, 1996.

[9] H. L. Yu, "Financial options and real options: Comparison and application," Shanghai University Finance \& Economics Press, Shanghai, 2003.

[10] A. K. Dixit and R. S. Pindyck, "Investment under uncertainty," Princeton University Press, Princeton, 1996.

[11] P. Mirowski and E. M. Sent, "Science bought and sold: Essays in the economics of science," University of Chicago Press, Chicago, 2002.

[12] J. A. Campbell, "Real options analysis of the timing of IS investment decisions," Information \& Management, Vol. 39, pp. 357-364, 2002.

[13] M. Benaroch, "A real options perspective of forthcoming," Journal of Management Information Systems, Vol. 1, pp. 23-31, 2002.

[14] F. Black and M. Scholes, "The pricing of options and corporate liabilities," Journal of Political Economy, Vol. 4, pp. 81-93, 1973.

[15] J. C. Hull, "Options, futures and other derivative securities (2th)," Prentice-Hall, Englewood Cliffs, NJ, 1993. 